\title{
Radon behavior investigation based on cluster analysis and atmospheric modelling
}

\author{
I. Gutiérrez-Álvarez ${ }^{\mathrm{a}, *}$, J.L. Guerrero ${ }^{\mathrm{a}}$, J.E. Martín ${ }^{\mathrm{a}}$, J.A. Adame ${ }^{\mathrm{b}}$, A. Vargas ${ }^{\mathrm{c}}$, J.P. Bolívara \\ ${ }^{a}$ Integrated Sciencies Department, University of Huelva, Spain \\ ${ }^{\mathrm{b}}$ Atmospheric Sounding Station - El Arenosillo, Atmospheric Research and Instrumentation Branch, National Institute for Aerospace Technology, INTA, Mazagón-Huelva, Spain \\ ${ }^{\mathrm{c}}$ Institut de Tècniques Energètiques, Universitat Politècnica de Catalunya, Spain
}

\section{A R T I C L E IN F O}

\section{Keywords:}

Atmospheric radon

WRF model

HYSPLIT

K-means clustering

Phosphogypsum

\begin{abstract}
A B S T R A C T
Radon measurements were performed in Huelva, a city located near a phosphogypsum repository in the SW of the Iberian Peninsula, between March 2015 and March 2016. The mean values of this gas oscillate between 5.6 and $10.9 \mathrm{~Bq} \mathrm{~m}^{-3}$ and maximum ranges between 36.4 and $53.4 \mathrm{~Bq} \mathrm{~m}^{-3}$. Radon shows the expected monthly variation with higher levels in November and December. Typical daily evolutions were also observed, with maximum between 06:00 and 08:00 UTC (Coordinated Universal Time) and minimum around noon. To extract daily radon patterns, the cluster technique of K-means was applied. Based on this classification, four different case study periods were analyzed in detail, describing two events with high radon levels and two with low radon. Local meteorology, back-trajectories computed with the HYSPLIT (Hybrid Single Particle Lagrangian Integrated Trajectory) model and meteorological fields from the WRF (Weather Research and Forecasting) model, were used to analyze the four case study periods selected. Low radon periods are characterized by the occurrence of non-pure breezes and maritime air masses from the Atlantic Ocean, whereas high radon periods occur under pure sea-land breezes affected by Mediterranean air masses. Factors such as meteorology or local emission sources alone may not be enough to explain the high radon events in the area. Other factors could be playing a major role in the radon levels. The obtained results indicate the contribution of radon transported from medium-long range, suggesting that, under specific weather conditions, the Gulf of Cadiz could act as a radon trap and the continental areas around the Western Mediterranean Basin could act as a radon source.
\end{abstract}

\section{Introduction}

Natural radon gas and its decay products are one of the main sources of natural exposure to ionizing radiation for the general population. UNSCEAR reported that the dose due to inhalation of this gas and the alpha-decay of its daughters represent more than $50 \%$ of the dose from all sources of radiation to the public. Outdoors radon measurements produce a global mean of $10 \mathrm{~Bq} \mathrm{~m}^{-3}$ with a wide range of long-term average concentrations for different typical locations going from $1 \mathrm{~Bq} \mathrm{~m}^{-3}$, for isolated small islands and coastal regions, to $100 \mathrm{~Bq} \mathrm{~m}^{-3}$ for sites with high radon exhalation over surrounding areas (UNSCEAR, 2000).

Interest in radon gas behavior is not only limited to its contribution to the radiation dose to the public. The half-life of radon, 3.8 days, is long enough to be a conservative tracer over the course of a single night, short enough to not accumulate in the atmosphere, and presents an order of magnitude gradient between the planetary boundary layer

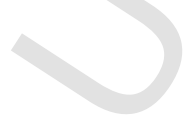

\footnotetext{
* Corresponding author.

Email address: isidoro.gutierrez@dfa.uhu.es (I. Gutiérrez-Álvarez)
}

and the lower troposphere (Moore et al., 1973; Chambers et al., 2015). These characteristics have positioned radon as a desirable proxy to measure and understand atmospheric stability variations (Porstendörfer et al., 1991; Vargas et al., 2015).

In addition, radon is a poorly soluble inert gas, insusceptible to dry or wet atmospheric removal processes, and its half-life is comparable to the residence time of certain air pollutants (i.e. $\mathrm{NO}_{\mathrm{X}}, \mathrm{SO}_{2}, \mathrm{O}_{3}, \mathrm{CH}_{4}$ ) and aerosols (Podstawczyńska, 2016). For these reasons, it has been used as a tracer gas on a global and regional scales (Wilkening, 1952; Burton and Stewart, 1960; Arnold et al., 2010; Grossi et al., 2018). Moreover, radon exhalation from inland areas are $2-3$ orders of magnitude greater than those from oceanic sources, originating a distinct differentiation between land and marine air masses (Schery and Huang, 2004). This allows the use of radon as a tracer of continental influence as well (Chambers et al., 2016; Botha et al., 2018). For these atmospheric transport studies, radon is considered to have a relatively consistent flux from ice-free terrestrial surfaces, depending on local soil parameters like composition, porosity, moisture and permeability (López-Coto et al., 2013; Karstens et al., 2015). 
Due to the interest and potential applications of radon, it is important to know what situations increase its concentration and what meteorological variables influence the most. One of the objectives of this paper consists of studying the peculiarities of the radon evolution throughout the day. In this sense, this work aims to identify daily characteristic patterns of radon and associate them to specific atmospheric conditions. To achieve this, k-means clustering was applied together with radon measurements in Huelva city, collected by a high sensitivity radon monitor, detailed meteorological information, atmospheric simulations and computation of air mass back-trajectories. To the best of our knowledge, this combination of techniques, simulations and different sources of information had never been used before to study the radon evolution in the vicinity of a NORM (Naturally-Occurring Radioactive Materials) repository.

In the city of Huelva, Spain, the fertilizer industry has generated phosphogypsum (PG) as a by-product for the last 45 years. These industries produced phosphoric acid using phosphate rock, which contains high levels of radioactive elements from the ${ }^{238} \mathrm{U}$ series. The phosphate rock is attacked with sulfuric acid, producing phosphoric acid and PG, breaking the equilibrium between ${ }^{238} \mathrm{U}$ and its daughters. Most of the uranium goes with the phosphoric acid while the radium, due to its similar chemical behavior to calcium, remains bounded with the PG (Bolivar et al., 1996; Mas et al., 2006). PG has ${ }^{226}$ Ra concentrations of $650 \pm 50 \mathrm{~Bq} \mathrm{~kg}{ }^{-1}$. This material, classified as NORM, was stacked in piles in the estuary of the Tinto river, less than $1 \mathrm{~km}$ from the city area, covering an extension about 1000 ha. Previous studies have shown that the PG repository is a potential source of radon gas (Bolivar et al., 1996; Dueñas et al., 2007; López-Coto et al., 2014; Hernández-Ceballos et al., 2015).

\section{Experimental and methods}

\subsection{Measurement site description}

The area of study is centered in the city of Huelva, located in the Southwest of the Iberian Peninsula, close to the coastline of the At- lantic Ocean and surrounded by the Tinto and Odiel rivers (Fig. 1) Huelva is in the northern part of the coastal outlet of the Guadalquivir Valley. This triangular-shaped area extends along the south of Spain oriented roughly from NE to SW with a vertex in the ENE. It is defined by the Sierra Morena hills to the north and the Baetic System mountains to the south.

The Guadalquivir Valley orientation, coupled with the influence of the SW synoptic winds produced in the Atlantic Ocean, outlines the wind regime in Huelva city. Summer shows high presence of SW winds (38\%) with speeds above $2 \mathrm{~ms}^{-1}$ and weaker winds coming from NW (27\%). In winter, winds blow mainly from NE (39\%) and NW (24\%). Autumn and spring present intermediate values transitioning from the predominantly SW winds in summer to NE winds in winter, with the NW component being almost constant throughout the year (Adame et al., 2010a; Hernández-Ceballos, 2012).

Coastal cities like Huelva usually present sea-land breezes that influence the atmospheric pollution circulation in the area. Two sea-land breeze patterns were identified in the region, which are pure breeze and non-pure breeze (Adame et al., 2010b). The pure breeze shows a first period in the afternoon (12:00 to 17:00 UTC), with $1.8-3.2 \mathrm{~m} \mathrm{~s}^{-1}$ winds blowing from SW, and a second part in the night (03:00 to 08:00 UTC), reaching an average maximum of $2.1 \mathrm{~m} \mathrm{~s}^{-1}$ with $\mathrm{NE}$ direction. On the other hand, the non-pure breeze regime presents a similar direction and slightly higher speeds in the afternoon, but then shifts to a NW direction after 00:00 UTC.

As explained before, the nearby region is characterized by the existence of a large repository of phosphogypsum (PG) located half a kilometer to the southeast of the inhabited area. This waste was stacked in piles reaching an extension similar to the urban area $\left(12 \mathrm{~km}^{2}\right)$ (Fig. 1) and height values that range from few meters in the edges to $25 \mathrm{~m}$ in the centre. The influence of these piles on the local radon behavior was established in previous works (López-Coto et al., 2014; Hernández-Ceballos et al., 2015).

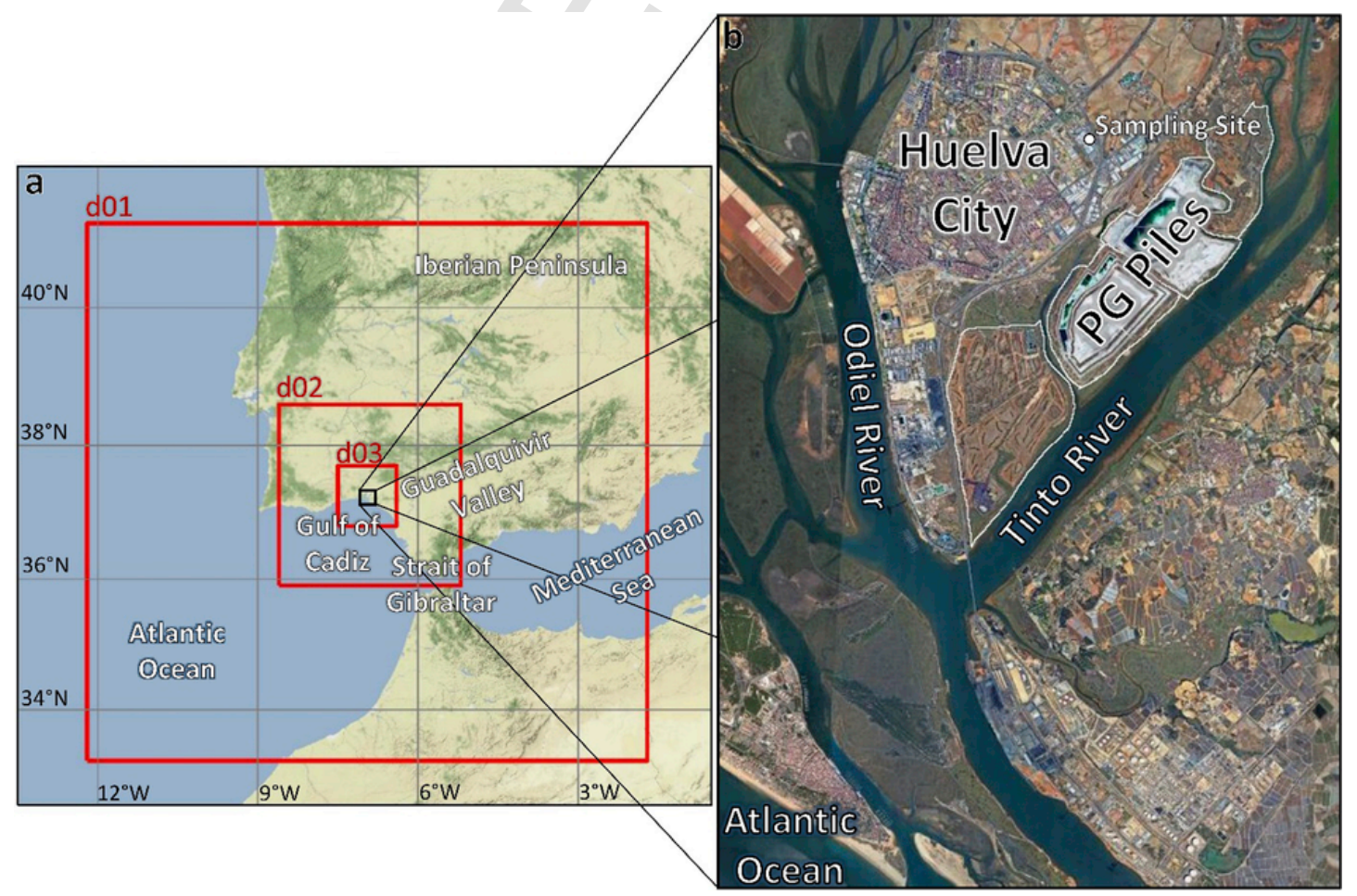

Fig. 1. Map of the Iberian Peninsula, its main features and simulation domains used in the WRF model (a) and a satellite picture of the Huelva city area (b). 


\subsection{Instrumentation and data collection}

The system employed to determine hourly ${ }^{222} \mathrm{Rn}$ concentrations was the Atmospheric Radon Monitor (ARMON). This device was manufactured by the FRYMA (Radiation Physics and Environment) research group following the guidelines of suggested by Vargas and Ortega, (2006) and Grossi et al. (2012). The ARMON carries out continuous air monitoring. It has a spherical detection volume of $20 \mathrm{~L}$, internally covered with a layer of an electrical conductor made of silver, with a PIPS (Passivated Implanted Planar Silicon) detector, which is electrically grounded and located at the top. Inside the detector, a sensor measures the absolute humidity and the temperature. The sphere has a $1 \mu \mathrm{m}$ pore filter at the air inlet to avoid the entrance of ${ }^{222} \mathrm{Rn}$ progeny. ${ }^{222} \mathrm{Rn}$ concentrations are considered constant during each hour and computed from the $\alpha$-activity of ${ }^{218} \mathrm{Po}$ cations produced by the ${ }^{222} \mathrm{Rn} \alpha$-decay in the detection volume. ${ }^{222} \mathrm{Rn} \alpha$-decay produces ${ }^{218}$ Po cations that are collected on the surface of the detector by applying $8 \mathrm{kV}$ between the detector and the inner sphere surface. The radon concentration is determined using the alpha particles produced by ${ }^{218} \mathrm{Po}$. The moisture level of the circulating air is kept under humidity lower than $2000 \mathrm{ppmV}$ of water in order to reduce the cation neutralization. The system efficiency depends on humidity. The monitor was calibrated at the INTE-UPC (Institut de Tècniques Energètiques - Universitat Politècnica de Catalunya) ${ }^{222} \mathrm{Rn}$ chamber (Vargas et al., 2004). The monitor efficiency was $0.35 \mathrm{cpm}$ per $\mathrm{Bq} \mathrm{m}^{-3}$ with a correction factor for the humidity inside the sphere of $1.9 \cdot 10^{-4}$ per ppmV. Thus, the MDC (minimum detected concentration) for this monitor is around $200 \mathrm{~m} \mathrm{~Bq} \mathrm{~m}^{-3}$ (Vargas et al., 2015). The uncertainty behaves lineally for radon values above $10 \mathrm{~Bq} \mathrm{~m}^{-3}$, being $8 \%$ for $10 \mathrm{~Bq} \mathrm{~m}^{-3}$ and $6 \%$ for $50 \mathrm{~Bq} \mathrm{~m}^{-3}$. However, lower radon concentrations showed higher uncertainties, e.g. $12 \%$ for $5 \mathrm{~Bq} \mathrm{~m}^{-3}$ and $18 \%$ for 2 Bq $\mathrm{m}^{-3}$.

The radon measurement station was placed inside "El Carmen" campus of the University of Huelva. The radon instrumentation was installed on a flat roof at $10 \mathrm{~m}$ above ground level (agl). The measurement period covered a whole year, from March 2015 to March 2016. The meteorological dataset was collected in a meteorological observatory located at a distance of $1.5 \mathrm{~km}$ to the northeast of the Campus (Fig. 1). The meteorological station measured at $16 \mathrm{~m}$ agl and provided results every $10 \mathrm{~min}$, which were hourly-averaged.

\subsection{Atmospheric models and clustering methodology}

The Weather Research and Forecasting (WRF-ARW) model was used to reproduce the atmospheric conditions of the study area. WRF is a state-of-the-art atmospheric modelling system designed for both meteorological research and numerical weather prediction. It is supported and maintained by the Mesoscale and Microscale Meteorology Laboratory (MMM) of the National Centre for Atmospheric Research (NCAR) and offers a host of options for atmospheric processes (Borge et al., 2008; Skamarock et al., 2008).

The WRF simulated area was defined with three domains centered on the Phosphogypsum piles $\left(37.24^{\circ} \mathrm{N}, 6.92^{\circ} \mathrm{W}\right.$ ) (Fig. 1). The resolutions of the three domains were related by a ratio of $1: 3$, as suggested Dudhia et al. (2014). Specifically, the resolutions were $9 \mathrm{~km}, 3 \mathrm{~km}$ and $1 \mathrm{~km}$ for the domains d01, d02 and d03, covering a squared-shape area of $900 \times 900 \mathrm{~km}^{2}, 300 \times 300 \mathrm{~km}^{2}$ and $100 \times 100 \mathrm{~km}^{2}$, respectively. As an input for the initial and boundary conditions, the ECMWF (European Centre for Medium-Range Weather Forecasts) ERA-Interim model dataset was used. The dataset contains atmospheric information with a temporal resolution of $6 \mathrm{~h}$ and spatial resolution of $0.25^{\circ}$ (approximately $28 \mathrm{~km}$ ) (Dee et al., 2011). The number of vertical levels in the WRF model was increased to 35 in order to improve the accuracy of the simulation (Seaman et al., 2009).

The scope of this study is limited on the description of the low atmosphere. For that reason, three different parametrizations of WRF for the Planetary Boundary Layer (PBL) computation were used. Only three parametrizations were employed in order to keep the time needed for the simulations at a reasonable level. More specifically: the default parametrization, i.e. the Yonsei University Scheme (YSU) (Hong et al., 2006), the Asymmetric Convective Model version 2 (ACM2) (Pleim, 2007) and the Mellor-Yamada-Janjic Scheme (MYJ) (Janjić, 1994). A sensitivity analysis over the study area was carried out using these three parametrizations.

Following the guidelines suggested by the European Union's Air Quality directive (Lükewille, 2008), different statistical parameters were used in order to evaluate the performance of the model parametrizations and its closeness to experimental measurements. In general, Gross Error (GE), Bias (BIAS) and the Index of Agreement (IOA) were applied (Pielke, 2002). In the case of wind speed, Root Mean Square Error (RMSE) was used instead of GE.

Planetary Boundary Layer (PBL) height data were obtained using the WRF output and compared for verification with the ERA-Interim meteorological fields, provided by the global meteorological model European Centre for Medium-Range Weather Forecast (ECMWF), with the highest resolution available: $0.125^{\circ} \times 0.125^{\circ}$ (Dee et al., 2011). This dataset provides a single value for every day at 12:00 UTC.

To evaluate the air mass pathways, back-trajectories were computed with the HYSPLIT (Hybrid Single-Particle Lagrangian Integrated Trajectory) model developed by NOAA's (National Oceanic and Atmospheric Administration) Air Resources Laboratory (ARL) (Draxler et al., 2018). Three-dimensional kinematic trajectories were computed with a 6-h interval, starting at 00:00, 06:00, 12:00, and 18:00 UTC, and a 96-h pathway at $100 \mathrm{~m}$ agl. The trajectories were calculated using ERA-Interim meteorological fields (spatial resolution of $0.5^{0} \times 0.5^{0}$ ), which were converted into the ARL standard format using the HYSPLIT model.

The K-means clustering technique was used with the aim of identifying patterns in the radon daily evolution (Everitt et al., 2011). The algorithm performs an iterative search to allocate the days in groups of similar features, using each time a lower number of groups until the desired number of clusters, $\mathrm{k}$, is reached. Initially, each day is considered as a single-day group. At each iteration, the algorithm computes the Euclidean distances between the groups and the closest two are joined together. As the number of iterations increases, groups are refined and reduced in number. The solution is reached when the number of groups is equal to the desired number of clusters and, therefore, each day is assigned to the closest cluster.

This clustering technique have been used successfully in atmospheric studies in the past (Adame et al., 2012; Domínguez-López et al., 2014; Vargas et al., 2015). A general description of clustering techniques can be found in Everitt et al. (2011) while a more applied and specific explanation appears in Beaver and Palazoğlu (2006).

As many clusters as possible were employed to identify special behaviors of the radon concentration. Nonetheless, special attention was paid to avoid clusters with similar features or microclusters that span over a small collection of days.

\section{Results}

\subsection{Radon overview: levels, monthly and daily evolutions}

In this study autumn season was considered to cover the period between September 23rd, 2015 and December 21st, 2015, whereas the winter season started on December 22nd, 2015 and ended on March 19th, 2016. The period between March 21st, 2015 and June 21st, 2015 corresponds to spring, and summer comprises the period from June 22nd, 2015 to September 22nd, 2015. The availability of the database is higher than $95 \%$ in summer and autumn. On the other hand, there is an important lack of data in spring, around 50\%, and a less serious lack of data in winter, around $20 \%$; both cases were associated with technical problems. However, these technical issues did not affect the conclu- 
sions of the study. In order to have an overview of the radon measurements, seasonal statistical parameters like maximum, 95th percentile, 50th percentile, 5th percentile, mean and minimum were calculated with hourly values (Table 1 ).

Spring, summer and winter have similar values for the mean (5.6-6.0 Bq m${ }^{-3}$ ), 50th percentile (3.4-3.9 $\mathrm{Bq} \mathrm{m}^{-3}$ ) and 95th percentile (19.4-20.5 $\mathrm{Bq} \mathrm{m}^{-3}$ ). 5th percentile is almost equal for spring, summer and autumn (1.2-1.3 $\mathrm{Bq} \mathrm{m}^{-3}$ ), and lower for the winter season $(0.4 \mathrm{~Bq}$ $\mathrm{m}^{-3}$ ). In contrast, autumn presents significantly higher results for the mean $\left(10.9 \mathrm{~Bq} \mathrm{~m}^{-3}\right)$, 50th percentile $\left(8.0 \mathrm{~Bq} \mathrm{~m}^{-3}\right)$ and 95th percentile (28.7 $\mathrm{Bq} \mathrm{m}^{-3}$ ), showing that there is a clearly distinct radon behavior in this season. These results are similar, although slightly higher than those obtained in 2013 by Hernández-Ceballos et al. (2015). They obtained $6.3 \mathrm{~Bq} \mathrm{~m} \mathrm{~m}^{-3}$ and $3.9 \mathrm{~Bq} \mathrm{~m}^{-3}$ for the yearly mean and 50th percentile, respectively. This discrepancy could be caused by the difference between the radon levels for autumn in each work, since our period of study presents higher radon levels in autumn months (Fig. 2).

It is worth noting that there is a considerable difference between maximum and 95th percentile values for every season, ranging from $16.9 \mathrm{~Bq} \mathrm{~m}^{-3}$ (winter) to $34.0 \mathrm{~Bq} \mathrm{~m}{ }^{-3}$ (summer). The maximum value tends roughly to be twofold or even threefold (summer) compared to 95th percentile. This suggests the existence of relative high-radon events with less than $5 \%$ occurrence throughout the year. It is also noticeable that the highest maximum values occurred in the seasons with the averaged highest exhalation rates from the soils of the area (López-Coto et al., 2014).

To investigate the average daily and monthly radon behavior in this area, the seasonal and monthly temporal evolution was studied (Fig. 2 ). The curves corresponding to the whole year (total) and each season follow the typical behavior to be expected along a day. The concentration of ${ }^{222} \mathrm{Rn}$ increases during the night as the atmospheric stability enhances the accumulation of ${ }^{222} \mathrm{Rn}$ in the lower layers of the atmosphere, and decreases during the daytime. However, the concentration

Table 1

Available data, maximum, minimum, mean, 95th, 50th and 5th percentiles for hourly ${ }^{222} \mathrm{Rn}$ concentration measurements (in $\mathrm{Bq} \mathrm{m}^{-3}$ ) for the different seasons and the whole year.

\begin{tabular}{llllll}
\hline & Spring & Summer & Autumn & Winter & Total \\
\hline Data (\%) & 47.3 & 98.7 & 98.9 & 77.7 & 80.5 \\
Maximum & 39.8 & 53.4 & 51.5 & 36.4 & 53.4 \\
95th percentile & 20.5 & 19.4 & 28.7 & 19.6 & 23.9 \\
50th percentile & 3.4 & 3.9 & 8.0 & 3.5 & 4.5 \\
Mean & 5.6 & 6.0 & 10.9 & 5.9 & 7.4 \\
5th percentile & 1.3 & 1.2 & 1.2 & 0.4 & 0.8 \\
Minimum & 0.1 & 0.0 & 0.1 & 0.0 & 0.0 \\
\hline
\end{tabular}

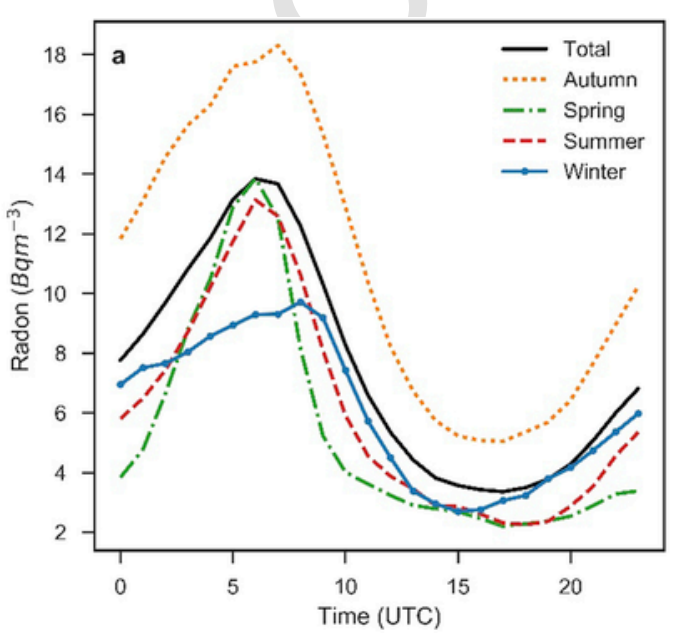

decreases during the daytime due to solar radiation, which breaks the nighttime stability and increases the vertical radon dilution. Regarding the uniformly elevated radon values observed in autumn, they can be explained by the wind speed and its origin, and the atmospheric stability associated to breezes. Autumn season usually shows a great proportion of winds arriving from the NE quadrant. NE direction is related to continental sources and radon fetch processes by the pure-breeze pattern (Hernández-Ceballos et al., 2015). In addition, autumn presents slower winds on average than the rest of the seasons, especially during nighttime, enhancing the radon accumulation.

Despite the general similarities found in the daily evolution of radon, there are distinct features between seasons. Winter shows the lowest maximum concentration $\left(9 \mathrm{~Bq} \mathrm{~m}^{-3}\right.$ ) but its peak has a wider temporal extension than the rest. The minimum radon concentration $\left(3 \mathrm{~Bq} \mathrm{~m}^{-3}\right)$ is reached around 16:00 UTC and then it slowly increases until 08:00 UTC, when it reaches its maximum again. In contrast, spring and summer have a higher $\left(12 \mathrm{~Bq} \mathrm{~m}^{-3}\right)$ but narrower peak centered at 06:00 UTC, a little earlier in spring than in summer. These peaks immediately decrease their concentration and reach their minimum $\left(2 \mathrm{~Bq} \mathrm{~m}^{-3}\right)$ around 17:00-18:00 UTC, which are the lowest concentrations of all seasons. Finally, autumn presents values above the other seasons for the whole day, as shown in Table 1. Its maximum $\left(18 \mathrm{~Bq} \mathrm{~m}^{-3}\right)$ is reached at 07:00 UTC, between those of summer and winter, with a peak wider than that observed in summer but narrower than that observed in winter. The minimum radon concentration $\left(5 \mathrm{~Bq} \mathrm{~m}^{-3}\right)$ is observed at 17:00 UTC.

The differences in peak locations could be explained by the sunrise and sunset hours for each season. In spring and summer (warm seasons) sunrise usually takes place around 05:00-06:00 UTC, whereas in autumn and winter (cold seasons) the first light appears at 06:00 or 07:00 UTC, respectively. In all cases, sunrise takes place roughly $1 \mathrm{~h}$ before the maximum concentration is reached. On the other hand, sunset occurs at 18:00 or 19:00 UTC in the warm season, and 17:00 or 18:00 in the cold one. Typically, the minimum of the average hourly ${ }^{222} \mathrm{Rn}$ concentration tends to occur before the sunset. This suggests that vertical dilution begins after dawn, decreasing radon concentrations, and stops before sunset, allowing radon to increase again during nighttime, repeating the cycle after the following sunrise.

Regarding the monthly radon averages seen in Fig. 2, it is observed that there was a high radon period in autumn (above $8 \mathrm{~Bq} \mathrm{~m}^{-3}$ ), a low interval in the two last months of winter and the first of spring (below $5 \mathrm{~Bq} \mathrm{~m}{ }^{-3}$ ) and an intermediate term that included most of spring and summer with values between 5 and $8 \mathrm{~Bq} \mathrm{~m}^{-3}$. The maximum concentration $\left(14 \mathrm{~Bq} \mathrm{~m}^{-3}\right.$ ) was reached in December 2015 while the minimum (4 $\mathrm{Bq} \mathrm{m}^{-3}$ ) was observed in March 2016. These results partially coincide with the data obtained in a previous study (López-Coto, 2011)

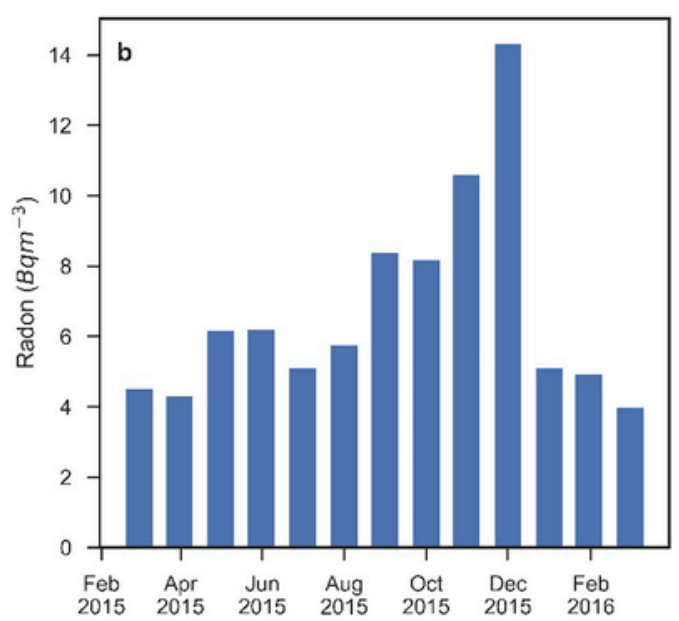

Fig. 2. Seasonal average daily evolution (a) and monthly average for radon (b). 
which included data from 1998 to 2006. In that case, the mean maximum for the whole period $\left(16.6 \mathrm{~Bq} \mathrm{~m}^{-3}\right)$ was also reached in December, whereas the mean minimum (4.6 $\mathrm{Bq} \mathrm{m}^{-3}$ ) was obtained in July, instead of March.

\subsection{Radon daily patterns: clustering analysis}

Different numbers of clusters were tested with the aim of characterizing the daily radon evolution throughout the year. Thus, a higher number of clusters were tested first. Tests with eight and seven clusters showed microclusters of less than five days and, therefore, were discarded. Six clusters presented two groups with almost identical features and were also discarded. Five clusters displayed different behaviors without duplicities or small clusters. Consequently, five was chosen as the optimal number of clusters.

Fig. 3 shows the $24 \mathrm{~h}$ hourly average for radon and several atmospheric variables, divided by clusters. The clusters were numbered from 1 to 5 in decreasing order of radon concentration. It can be seen that the general daily behavior for radon consisted of an increase in the first hours of the day, followed by a significant decrease in radon concentration after sunrise. With the exception of cluster 2 , the concentration levels did not exceed $5 \mathrm{~Bq} \mathrm{~m}{ }^{-3}$ in the afternoon.

Furthermore, Table 2 shows the distribution of clusters throughout the year. Clusters 4 and 5 are present in almost every season while clusters 1 and 2 show higher presence in autumn. Finally, cluster 3 seems to appear more frequently in spring, summer and autumn. However, cluster presence in spring may be higher due to the lack of data in this season.

The first cluster represents days with a significant increase in radon concentration, reaching values above $30 \mathrm{~Bq} \mathrm{~m}^{-3}$, in the hours before sunrise and a quick decrease in the morning. This group, the least common, includes 17 days ( $6 \%$ of the total), usually isolated in one or at most two successive days, appearing mostly in the autumn season. Regarding the atmospheric variables, this cluster shows a behavior similar to most of the other clusters. Cluster 1 days are characterized by relatively high temperature and low relative humidity, in relation to those in other clusters. Finally, first cluster also presents the highest PBL height of all groups (higher than $1500 \mathrm{~m}$ ) at 12:00 UTC.

The second cluster consists of 30 days (11\%) and occurs mainly in autumn. The diurnal pattern displays a delayed peak in radon concentration, around 08:00 UTC, reaching almost $30 \mathrm{~Bq} \mathrm{~m}^{-3}$. This group does not decrease the radon levels in the afternoon as much as the other clusters, staying above $8 \mathrm{~Bq} \mathrm{~m} \mathrm{~m}^{-3}$ between 12:00 and 20:00 UTC and starting to rise again around 16:00 UTC in the afternoon. This behavior is accompanied by the lowest PBL height, and lowest wind speed, consequently leading to a lesser horizontal dispersion and vertical mixing. These conditions may enhance the radon accumulation in the lowest atmospheric layers. This cluster shows a distinctive behavior for temperature, humidity and pressure. In addition, PBL height and wind speed are significantly lower than those in the other clusters. Reduced wind speeds and a shallow PBL height, which involve a relatively shallow mixing layer, may explain the slight decrease of radon concentration in the daytime.

The third cluster shows features similar to those of the first cluster. Radon concentration grows as fast as in the cluster 1 in the first $5 \mathrm{~h}$ of the day but its increase appears truncated afterwards. This behavior may be explained by the wind speed curve. Wind speed in cluster 3 starts to rise earlier than in the first cluster and remains high during the day. This cluster includes 29 days (11\% of the total) mainly appearing in summer and autumn.

The fourth cluster displays a slight increase of radon from 00:00 to 07:00 and a decrease afterwards. The 56 days (21\%) that belong to this cluster seem to appear throughout the whole year with a similar probability. In general, atmospheric variables do not show any special features that differentiate this cluster from others. However, wind speed between 10:00 UTC and 17:00 UTC shows lower values in this cluster than for the rest of them. Looking at radon concentration and wind speed, this group seems like an intermediate state between clusters 2 and 5 .

Finally, the fifth cluster presents radon concentrations almost flat for the entire duration of the day, staying in the vicinity of $5 \mathrm{~Bq} \mathrm{~m} \mathrm{~m}^{-3}$ and always under the radon levels showed by the other clusters. It is the most common cluster including 141 days (52\%) with a higher
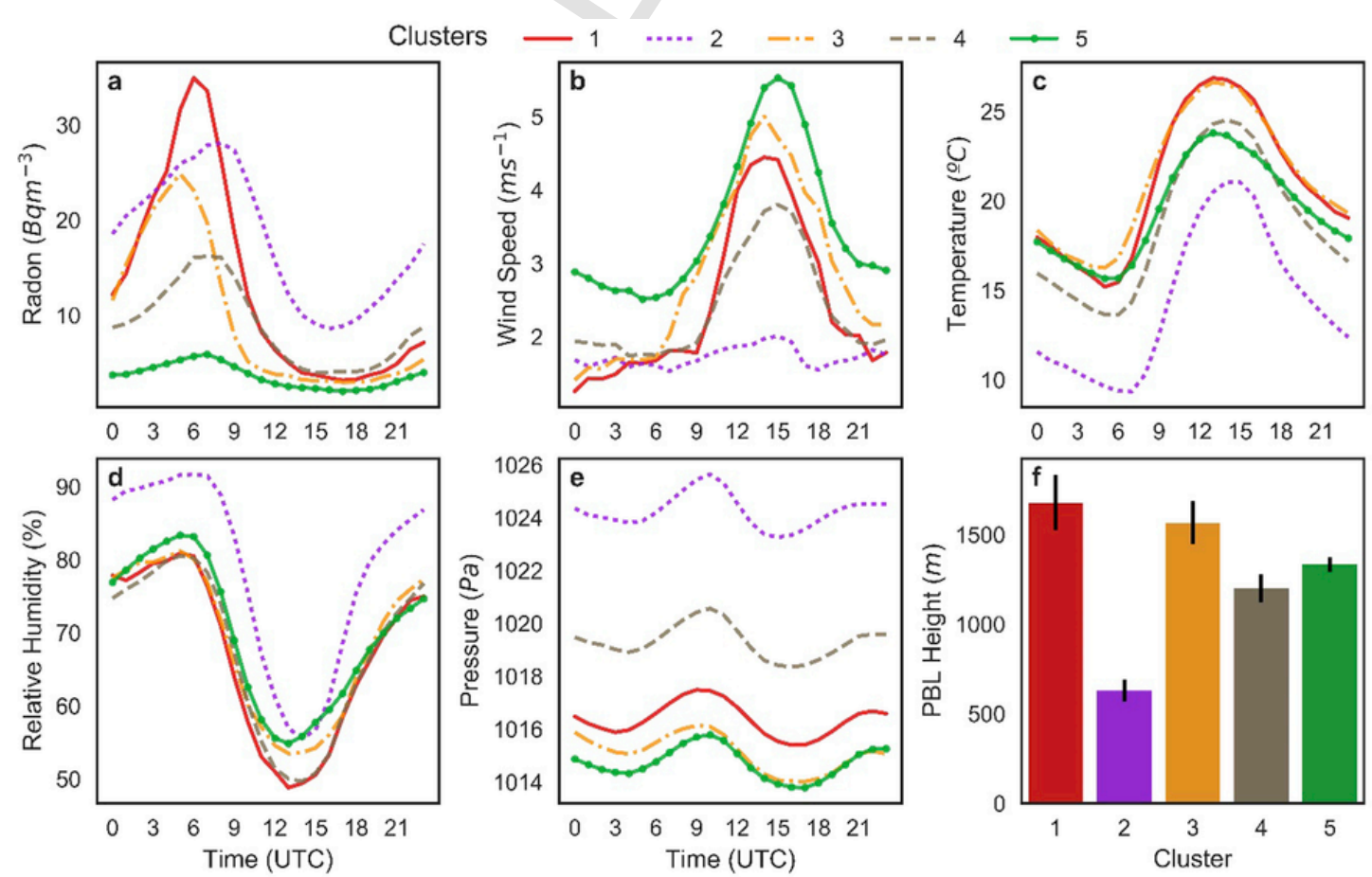

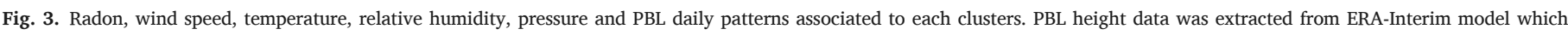
provides one daily value at 12:00 UTC. 
Table 2

Percentage of cluster days for each season and for the whole year.

\begin{tabular}{llllll}
\hline Cluster & Spring & Summer & Autumn & Winter & Year \\
\hline 1 & $2.7 \%$ & $6.0 \%$ & $11.4 \%$ & $1.6 \%$ & $6.3 \%$ \\
2 & $0.0 \%$ & $0.0 \%$ & $26.1 \%$ & $10.9 \%$ & $11.0 \%$ \\
3 & $16.0 \%$ & $13.3 \%$ & $11.4 \%$ & $3.1 \%$ & $10.7 \%$ \\
4 & $13.5 \%$ & $20.5 \%$ & $22.0 \%$ & $23.4 \%$ & $20.6 \%$ \\
5 & $67.6 \%$ & $60.2 \%$ & $29.6 \%$ & $61.0 \%$ & $51.5 \%$ \\
\hline
\end{tabular}

probability in summer and winter than in spring and autumn. The days belonging to this group show a higher wind speed at every hour in the day. It is worth mentioning the higher wind speed in the night hours (21:00 to 09:00 UTC).

This paper is focused on the study of clusters 1, 2 and 5, since they show extreme conditions in radon daily variation. The first cluster includes the days with the highest radon concentrations, condensed in a narrow peak. The second cluster includes those days that do not reduce radon levels under $5 \mathrm{~Bq} \mathrm{~m}^{-3}$ after sunrise, unlike all the other groups. Finally, the fifth cluster contains most of the days, showing constant radon levels throughout the day that never exceed $8 \mathrm{~Bq} \mathrm{~m} \mathrm{~m}^{-3}$.

\subsection{Radon study cases}

To perform a detailed study of the radon behavior using the cluster classification, four periods were selected as representative of the typical radon/meteorological patterns. Two periods with high radon levels, from September 26th to October 3rd, 2015, defined as "case A", and November 30th to December 7th, 2015, defined as "case B", were chosen. These periods show radon patterns classified within clusters 1 and 2. Another two periods were selected with low radon concentrations: 27 July to 3 August 2015, defined as "case C", and finally the "case D" from 3 to 10 January 2016. Both periods are characterized by days belonging to cluster 5 .

Events were selected taking into account typical weather and radon patterns of the region, as previously described in section 2.1. The first two periods, $\mathrm{A}$ and $\mathrm{B}$, correspond to mesoscale processes, i.e. a pure-breeze pattern, at the beginning and end of autumn, related to warm and cold seasons, respectively. Period C covers days with a non-pure breeze regime in summer. Finally, the fourth period, D, is governed by the synoptic scale, characterized by SW airflows coming from the Atlantic Ocean with higher wind speed (see Table 3).

With the aim of analyzing the impact of meteorological conditions in radon variations, the WRF model was used. In order to know which WRF parametrization was optimal in each case study, a sensitivity analysis was carried out for surface meteorological variables: temperature, relative humidity and wind (speed and direction). The parameters mentioned in Section 2.3 were calculated (GE, BIAS, IOA and RMSE) to study the performance of the model (Table 2).

In each case, the best parametrization was used, prioritizing performance in wind speed and direction. Appling this criteria, in the study cases with high radon (A and B) MYJ parametrization shows the best results, whereas for the low radon events the YSU scheme could be applied. It should be noted that, when choosing the best parameters for case A, MYJ was selected due its significantly better performance for wind direction. Despite not being the best option for wind speed, the differences between parametrizations were low enough to consider not using the best of them for wind speed.

Moreover, atmospheric transport pathways for both high and low radon case study periods were analyzed using back-trajectories computed with the HYSPLIT model (Fig. 4), and meteorological fields obtained from the WRF model.

\subsubsection{Case study periods with high radon levels}

Events with high radon levels were defined as case A and case B. The evolution of wind data for case A shows meteorological conditions governed by the mesoscale in the early autumn season from September 26th to October 3rd, 2015, specifically with the development of pure sea-land breezes (Fig. 5). This period is characterized by high radon peaks with days corresponding mostly to cluster 1 . These days show narrow peaks in the first half of the morning, usually between 04:00 and 08:00 UTC. The maximum Rn concentration ranges from over $20 \mathrm{~Bq} \mathrm{~m}^{-3}$ to $50 \mathrm{~Bq}$ $\mathrm{m}^{-3}$. The case study period finishes with a day with low radon concentrations assigned to cluster 5 , in which the breeze period is over and back-trajectories come from the Atlantic Ocean.

PBL height and wind speed are two key factors that affect the radon levels by means of vertical and horizontal dispersion, respectively. The hourly evolution of the PBL shows maximum diurnal values ranging from 1000 to $2000 \mathrm{~m}$ for cluster 1 . However, it is well known that high radon levels occurred in nighttime when the nocturnal inversion layer is formed. PBL height shows a strong influence on radon concentration since the start of the decrease in radon levels coincides with the rise of PBL in the morning. Days with low mixing layer height are associated with high radon for the next night, for instance, September 26th and September 30th, 2015. On the other hand, days with high mixing layer are associated with low radon levels, as seen for September 29th to September 27th and October 1st, 2015.

The reason behind the change from cluster 1 to cluster 3 on September 29th could be related to horizontal dispersion. As can be seen in Fig. $5 c$, the wind pattern in the local area for September 29th at 04:00 UTC is characterized by NE winds with speeds around $5 \mathrm{~ms}^{-1}$. However, the next day at the same hour (Fig. 5d) the situation did not develop the same wind speeds in the region, allowing radon concentrations to reach higher levels. This difference in the local wind regime on

Table 3

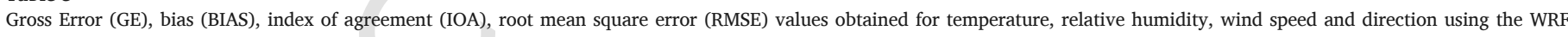

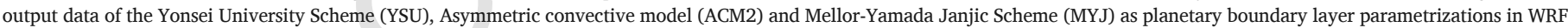
and experimental observations, for the four case study periods defined as A to D.

\begin{tabular}{|c|c|c|c|c|c|c|c|c|c|c|c|c|}
\hline \multirow[t]{2}{*}{ Period } & \multirow[t]{2}{*}{ Simulation } & \multicolumn{3}{|c|}{ Temperature } & \multicolumn{3}{|c|}{ Relative Humidity } & \multicolumn{3}{|c|}{ Wind Speed } & \multicolumn{2}{|c|}{ Wind Direction } \\
\hline & & GE & BIAS & IOA & GE & BIAS & IOA & RMSE & BIAS & IOA & GE & BIAS \\
\hline \multirow[t]{3}{*}{ A } & YSU & 1.53 & -1.16 & 0.95 & 8.42 & -3.82 & 0.88 & 1.51 & 0.64 & 0.72 & 37.50 & -1.50 \\
\hline & ACM2 & 1.39 & -1.03 & 0.96 & 7.40 & -2.90 & 0.93 & 1.41 & 0.58 & 0.74 & 44.51 & -2.83 \\
\hline & MYJ & 1.30 & -0.90 & 0.97 & 7.35 & -3.35 & 0.92 & 1.63 & 0.95 & 0.74 & 34.62 & 0.31 \\
\hline \multirow[t]{3}{*}{ B } & YSU & 1.16 & -1.07 & 0.97 & 7.06 & -5.73 & 0.92 & 1.62 & 1.31 & 0.38 & 34.22 & 11.82 \\
\hline & ACM2 & 1.13 & -1.00 & 0.97 & 6.87 & -5.74 & 0.92 & 1.61 & 1.28 & 0.39 & 33.13 & 10.16 \\
\hline & MYJ & 1.21 & -0.98 & 0.97 & 5.99 & -3.42 & 0.94 & 1.81 & 1.53 & 0.39 & 26.50 & 1.07 \\
\hline \multirow[t]{3}{*}{$\mathrm{C}$} & YSU & 1.28 & -0.18 & 0.97 & 8.49 & -3.63 & 0.89 & 2.16 & 1.12 & 0.66 & 33.69 & 11.31 \\
\hline & ACM2 & 1.37 & 0.00 & 0.96 & 8.77 & -5.07 & 0.89 & 2.33 & 1.23 & 0.63 & 34.43 & 11.43 \\
\hline & MYJ & 1.48 & -0.34 & 0.96 & 8.52 & -1.53 & 0.89 & 2.65 & 1.82 & 0.61 & 30.86 & 13.80 \\
\hline \multirow[t]{3}{*}{$\mathrm{D}$} & YSU & 1.38 & -1.14 & 0.91 & 4.64 & -1.83 & 0.88 & 1.30 & 0.20 & 0.88 & 22.31 & 3.56 \\
\hline & ACM2 & 1.23 & -0.70 & 0.93 & 6.46 & -5.51 & 0.82 & 1.42 & 0.61 & 0.86 & 20.54 & 6.21 \\
\hline & MYJ & 1.50 & -1.29 & 0.90 & 5.06 & 0.07 & 0.85 & 1.67 & 0.73 & 0.84 & 25.69 & 5.48 \\
\hline
\end{tabular}



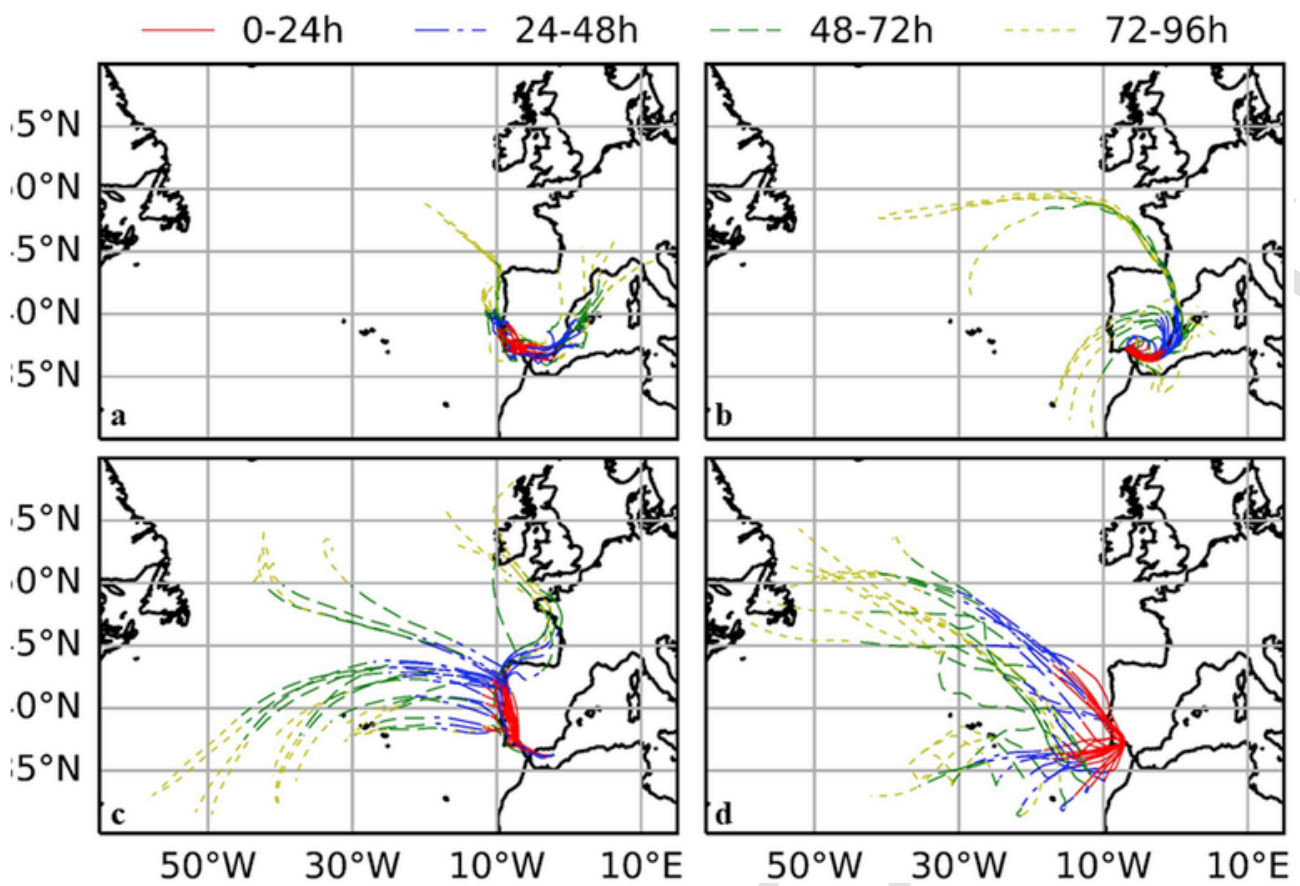

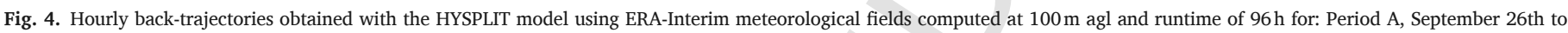

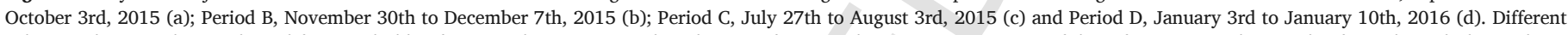

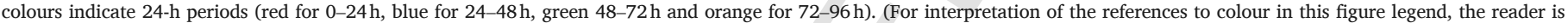
referred to the Web version of this article.)

the first hours of the day caused the change from cluster 1 to cluster 3 . As previously explained, the main difference between cluster 1 and 3 appears to be the existence of higher wind speeds in the early morning, inhibiting the radon growth in the first half of the day.

During the day, air masses coming from the Mediterranean Sea arrived to the Gulf of Cadiz. The pathways performed by these air masses can be observed in the back trajectories obtained with the HYSPLIT model (Fig. 4a). These airflows can transport radon, which could be captured by the marine breeze and channeled through the Guadalquivir valley inland. In this case, the Gulf of Cadiz could act as a radon gathering point where radon from the Mediterranean area could be accumulated.

However, high radon concentrations are not observed on diurnal time in the coastal area of Huelva due to the high PBL height, which enhances its dilution in the lower atmosphere layers. At night, NE flows dominate the nocturnal breeze regime. The wind fields obtained with WRF show these airflows, and also the SE flows originated in the Mediterranean Sea. These airflows from the southeast impact the low-middle area of the Guadalquivir valley as reflected by the radon peak observed on September 29th at 04:00 UTC (Fig. 5c). However, the radon peak on September 30th occurred with airflows from NE, although with low wind speeds (Fig. 5d), causing atmospheric stagnation and radon accumulation in the lower layers of the atmosphere.

The second case study period selected with high radon levels, defined as $\mathrm{B}$, is also meteorologically determined by mesoscale processes, a pure sea-land breeze pattern (Fig. 6a) similar to case A, but in the cold season. Thus, the development of the diurnal regime of the breeze is shorter (Fig. 6b).

According to radon cluster classification, this period includes days belonging mainly to cluster 2 with maximum hourly values ranging between 28 and $34 \mathrm{~Bq} \mathrm{~m}^{-3}$, which are lower than those for case A. As was expected, the height of the daytime PBL is significantly lower than in the previous case, being about $1000 \mathrm{~m}$ on average. A shallower mixing layer should enhance the radon accumulation in the atmosphere, as it reduces its vertical dilution. In addition, this term shows the lowest wind speeds of all studied periods; this fact also enhances the increase in radon levels throughout the week. Despite the low PBL height and reduced wind speeds, radon levels did not reach higher maximum concentrations than those in case A. Therefore, other factors could be affecting the radon concentrations. One of them might be the lower radon exhalation rates observed in the cold season than in the warm season (López-Coto et al., 2014).

As in the previous case study, wind fields obtained from the WRF model were used to study radon. Fig. $6 \mathrm{c}-\mathrm{d}$ shows the wind field at the time the radon peaks on December 3rd and December 6th, 2015 occurred. Even though this event happened in winter, the surface wind is similar to that of the summer case. The radon peaks could be associated with NE airflows in the study area. However, their origin is related to SE flows coming from the Mediterranean Sea that reached the Guadalquivir valley. The back trajectories computed with the HYSPLIT model for this period confirm this situation (Fig. 4b), with a clear transport from the Mediterranean area.

Therefore, the radon concentrations measured in the Gulf of Cadiz and its coastal area under sea-land breeze conditions could have two additional courses: i) radon transported during the daytime from the Gulf of Cadiz to the Guadalquivir valley which returns to the coast during nighttime, and ii) radon that originates in the Mediterranean area before reaching the Strait of Gibraltar. The origin of both cases could be the air masses from the Western Mediterranean Basin. During the day, they reach the Gulf of Cadiz and become trapped by the diurnal regime of the breeze, which could be defined as an indirect transport. During the night, the nocturnal breeze is affected by SE airflows coming from the Mediterranean Sea, which could be defined as a direct transport.

\subsubsection{Case study periods with low radon levels}

Two case study periods were selected as representative of low radon levels. The case study period defined as C, occurred in summer from July 27th to August 3rd, 2015 under meteorological conditions governed in the lower atmosphere by a non-pure breeze pattern (Fig. 7a). Out of the influence area of the sea-land breezes, the air masses coming from the West coast of the Iberian Peninsula and the Atlantic 

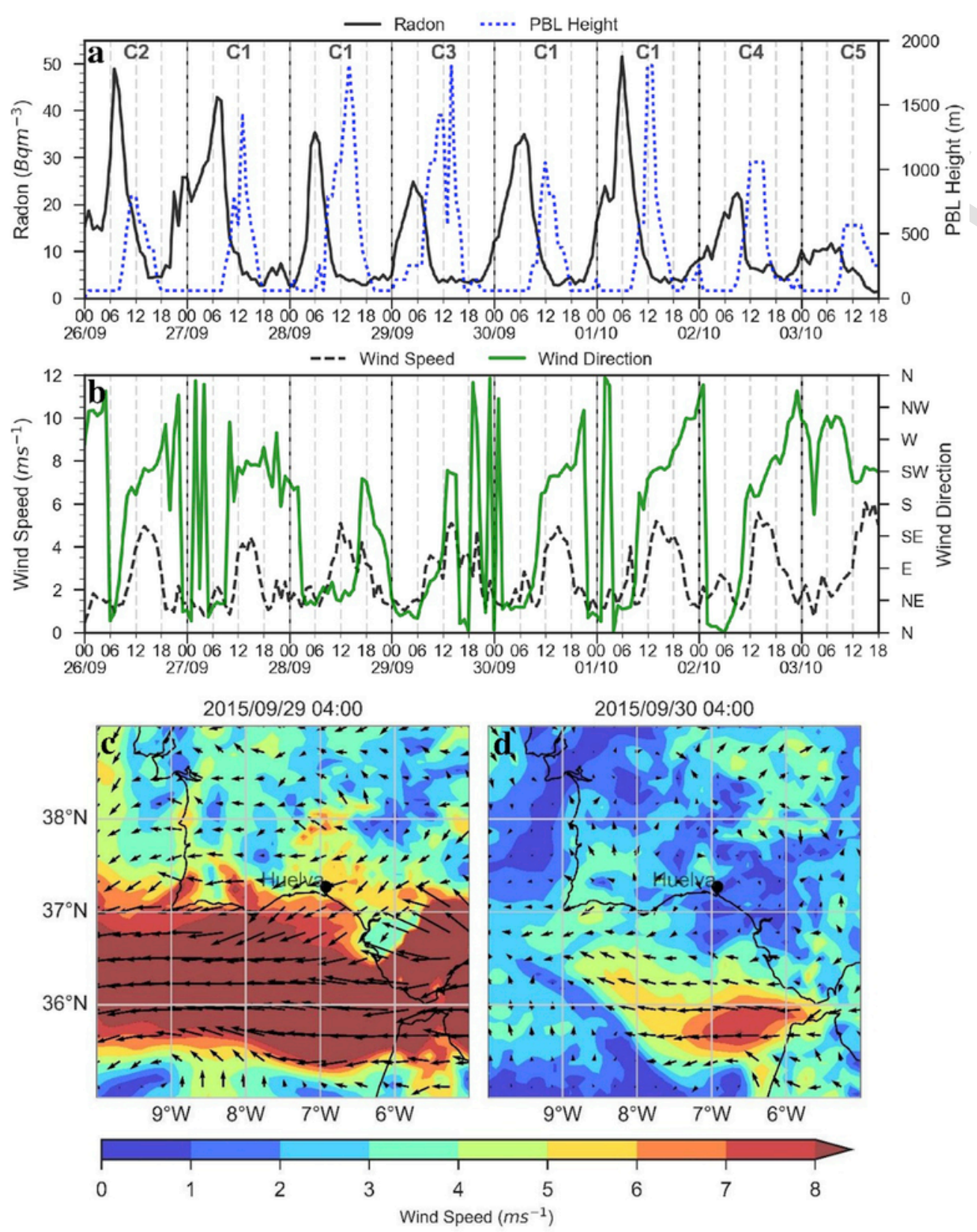

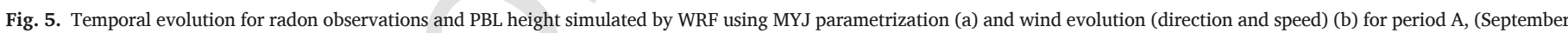

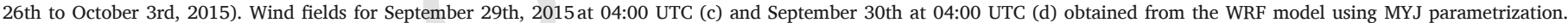
Cluster membership is indicated in the top of each plotted diurnal cycle.

Ocean show a clear maritime origin (Fig. 4c). The wind speeds are higher than those observed in the two cases with high radon levels, reaching values above $2 \mathrm{~m} \mathrm{~s}^{-1}$, which could enhance the horizontal transport and, subsequently, the dispersion of radon originated in the local/regional area. Simulations for PBL height present peaks usually above $1500 \mathrm{~m}$, similar to those obtained for case A, a period of pure breeze in autumn. These facts, i.e. higher horizontal dispersion and elevated PBL within the diurnal time, are suitable conditions for low radon concentrations. On August 2nd, 2015, the only day belonging to cluster 4 , there is an interval of time during nighttime where PBL drops near zero for several hours and a pure breeze regime takes place, allowing radon concentrations to increase. As a consequence, most days of this interval belong to cluster 5, presenting radon levels below $5 \mathrm{~Bq}$ $\mathrm{m}^{-3}$.

There is an exception on August 2nd, where radon is significantly higher than in the neighboring days, starting to rise at around 04:00 in the morning and reaching $25 \mathrm{~Bq} \mathrm{~m}^{-3}$ at 06:00. The day before, August 1st, shows a weak increase in the first hours of the day but never exceeds $10 \mathrm{~Bq} \mathrm{~m}{ }^{-3}$; in this day, the wind continued to blow from NW, as shown by the wind fields (Fig. 7c). PBL heights and wind speeds are similar for the first half of each day. However, the wind has NE direction between 02:00 and 06:00 UTC for August 2nd, 2015. In addition, in the wind field obtained from WRF (Fig. 7d) it can be observed that there are airflows from SE reaching the Guadalquivir valley, suggesting a relation between the radon increase and the arrival of Mediterranean air flows. These results are supported by the back trajectories computed in this case study period, where a couple of trajectories originate from the Mediterranean Sea (Fig. 4c). 

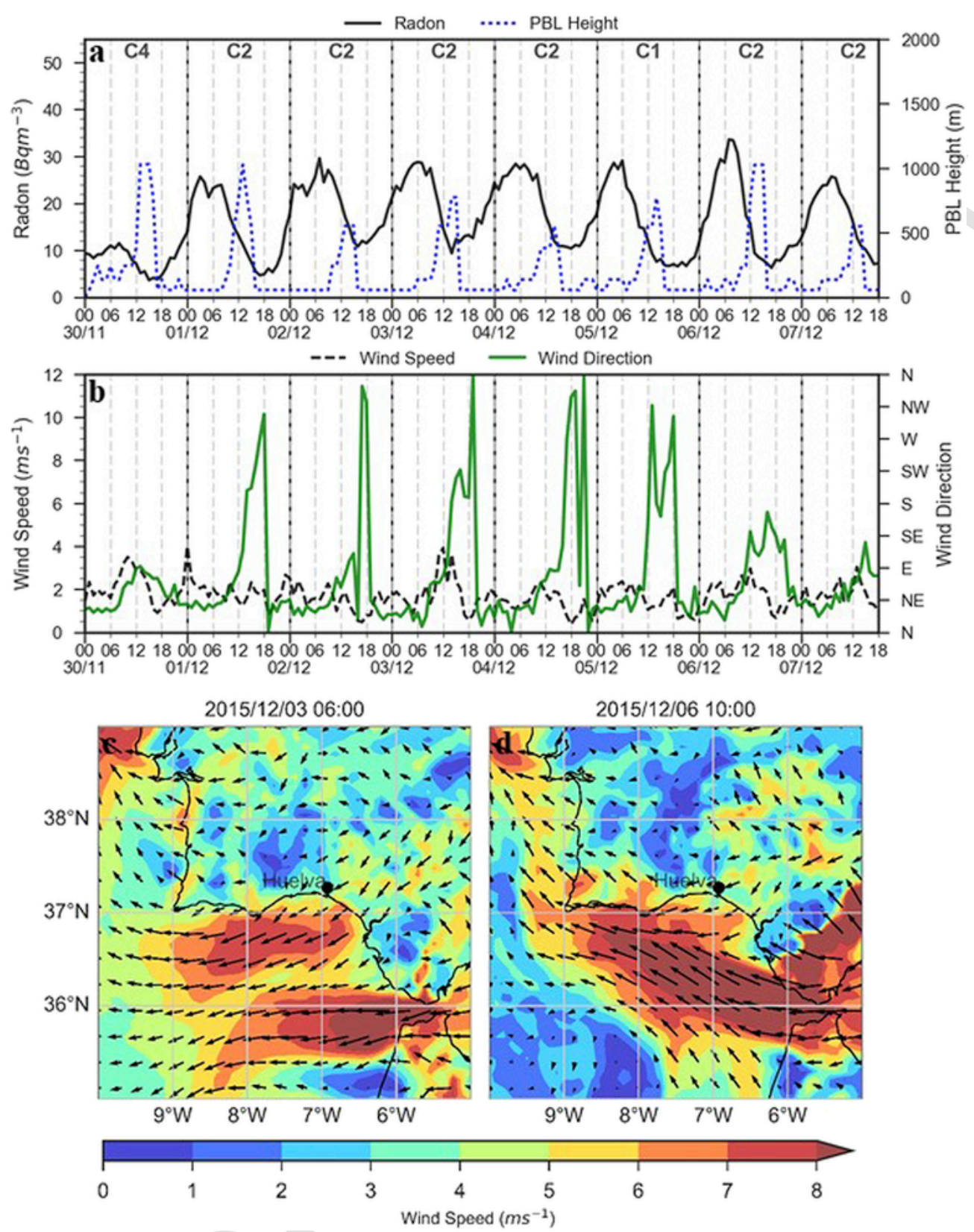

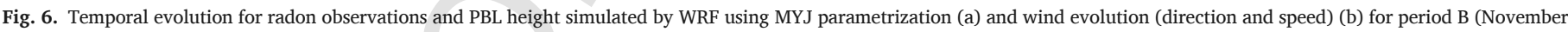

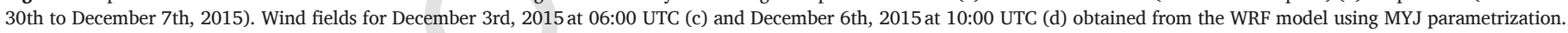
Cluster membership is indicated in the top of each plotted diurnal cycle.

The last period covers from January 3rd to January 9th, 2016 and was governed by synoptic winds coming from SW. Radon concentrations, along with PBL and wind evolution, are shown in Fig. 8a-b. This case consists of seven days belonging to cluster 5 where only two days surpassed $5 \mathrm{~Bq} \mathrm{~m}{ }^{-3}$, January 3rd and January 6th, 2016. These days show a decrease in PBL height in the previous hours. Case D is characterized by air masses coming from the Atlantic Ocean, reaching the southwest region of the Iberian Peninsula (Fig. 4d) with airflows blowing from the SW-NW sector with wind speeds reaching values above $6 \mathrm{~m} \mathrm{~s}^{-1}$ (Fig. 8b), which can also be seen in the wind fields from WRF for January 5th at 05:00 UTC (Fig. 8c).

A radon increase was observed on January 6th, 2016. A detailed study reveals a period with low wind speed coming from NE between 06:00 and 11:00 UTC (Fig. 8d) associated with a decrease in PBL height, which are suitable conditions for radon accumulation. How- ever, in this case the radon increase is significantly lower than in the study cases with high radon levels.

\section{Summary and conclusions}

Radon measurements were collected in the SW of the Iberian Peninsula from March 2015 to March 2016. An overview of its concentration and monthly and daily evolutions was carried out. The maximum values ranged between 36.4 and $53.4 \mathrm{~Bq} \mathrm{~m}^{-3}$, whereas the mean values ranged between 10.9 and $5.6 \mathrm{~Bq} \mathrm{~m}{ }^{-3}$. Autumn showed higher mean and 50th percentile values than the rest of the seasons, whereas the minimum values remained the same throughout the year. In all seasons, the maximum values were around 1.5-3 times higher than those of 95th percentile, suggesting the existence of high-radon events with less than $5 \%$ occurrence. 

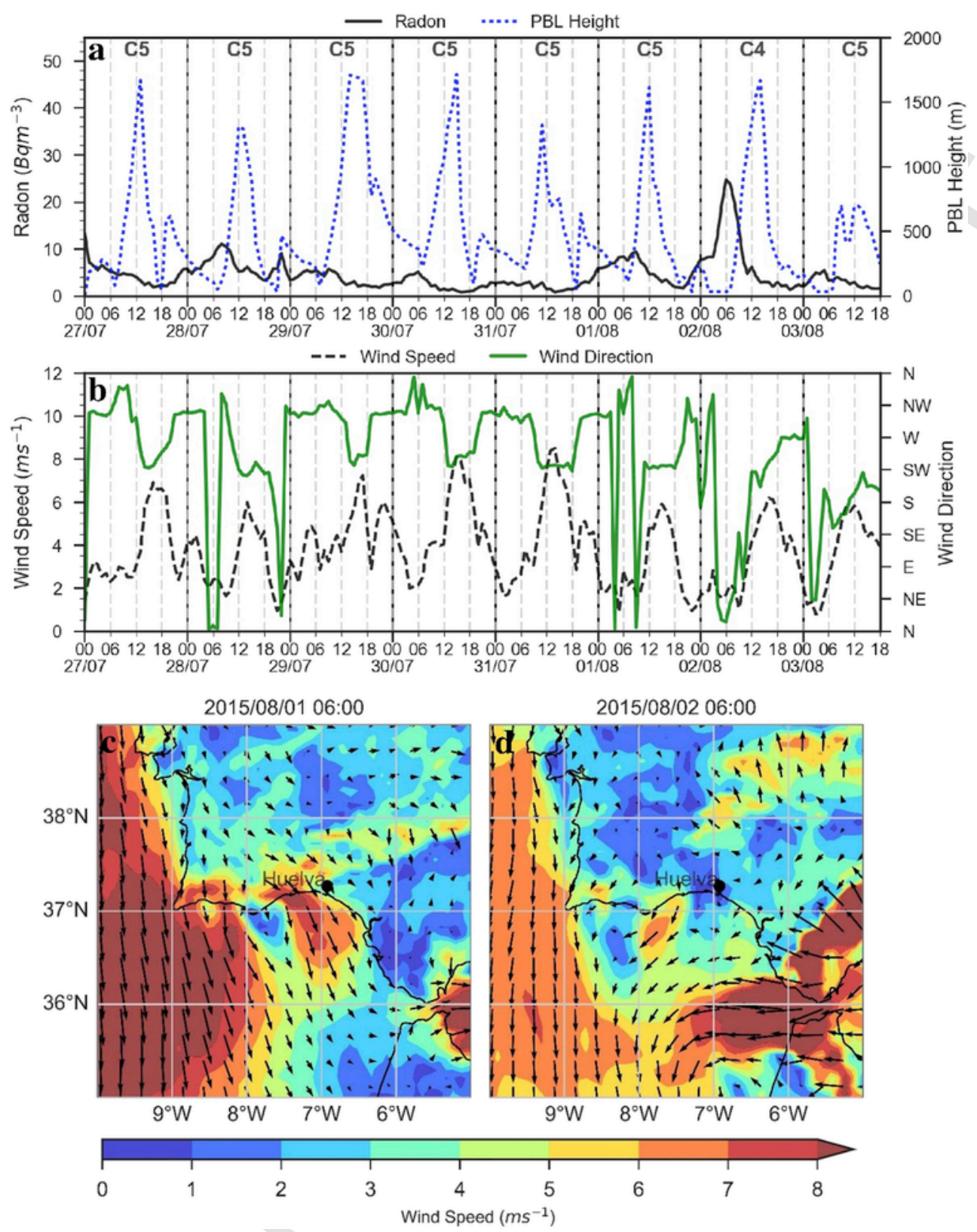

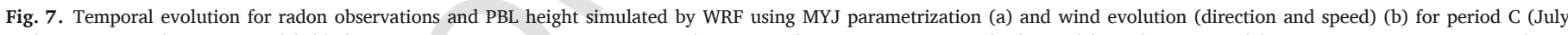

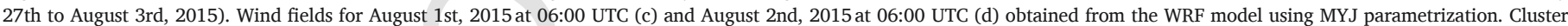
membership is indicated in the top of each plotted diurnal cycle.

Daily variations showed the expected behavior, increasing during nighttime and decreasing during the day. Depending on the season, minimum values ranged between 2 and $5 \mathrm{~Bq} \mathrm{~m}^{-3}$ and took place $2 \mathrm{~h}$ before sunset, and the maximum values occurred $1 \mathrm{~h}$ before sunrise, reaching values around $9-8 \mathrm{~Bq} \mathrm{~m}^{-3}$. Twenty-four-hour radon daily concentrations in autumn remained higher with respect to other seasons for every hour. On the other hand, there were radon peaks in November and December, around $11-14 \mathrm{~Bq} \mathrm{~m}{ }^{-3}$, whereas the minimum concentrations appeared from January to April, never exceeding $5 \mathrm{~Bq} \mathrm{~m}^{-3}$.

In order to determine the daily variability, a cluster analysis was applied to the radon measurements. Five different groups were defined as daily radon patterns. Clusters 1 and 2 represented high radon days, the former characterized by a single high peak around 06:00 UTC followed by a sharp decrease, and the latter described by a wider but lower peak and the absence of an effective radon dispersion in the afternoon. Cluster 5 represented days with almost no radon increase dur- ing the whole day while clusters 3 and 4 showed intermediate behaviors between clusters 1 and 2, respectively, and cluster 5 .

Based on this classification, four different case study periods were studied in detail, two of them describing events with high radon levels and the other two depicting low radon situations. These periods were analyzed using observations of the local meteorology, computation of back-trajectories with the HYSPLIT model, and wind fields and PBL height, both simulated with the WRF model. The analysis of these periods confirmed that situations of atmospheric stability, i.e. low PBL height and wind speed, increase radon concentration by reducing its vertical and horizontal dispersion.

Moreover, back-trajectories showed that high-radon periods could be related to air masses that originate in the Mediterranean Sea. In these periods, radon concentrations increased during the night with atmospheric stability and lower wind speeds under the influence of NE airflows, which are characteristic of the nocturnal regime of the breeze. 

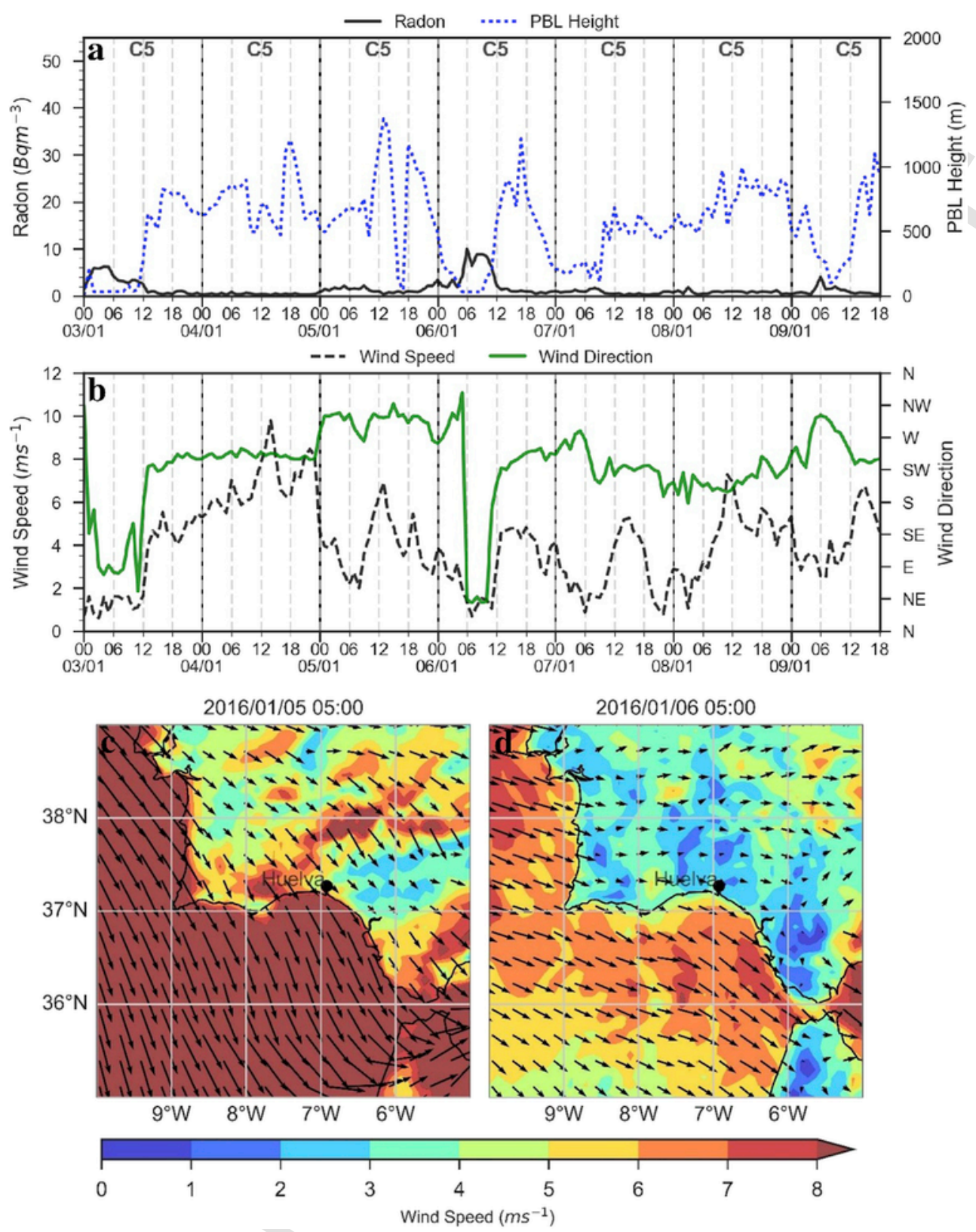

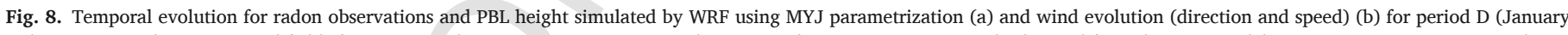

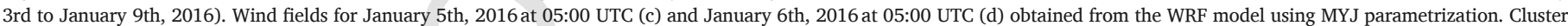
membership is indicated in the top of each plotted diurnal cycle.

Thanks to the wind field obtained from the WRF model, an additional double contribution was identified. In contrast to the local influence related to the PG piles, these contributions could be associated to the medium-long radon transport and could reach the study area in two ways: indirect transport from the Gulf of Cadiz, travelling to the Guadalquivir valley during the day and coming back with the nocturnal regime of the breeze, and, direct transport from the Mediterranean Sea, carried by SE flows reaching the low-medium Guadalquivir valley through the SE of the Iberian Peninsula.

On the other hand, low-radon situations are more strongly related to air masses coming from the Atlantic Ocean, corresponding to non-pure sea-land breeze patterns developed with synoptic forcing (wind blowing from NW) and periods with SW flows. In these two cases there was limited or no influence of Mediterranean flows.

In conclusion, high radon events were always accompanied by air masses originated in the western Mediterranean area under a pure- breeze regime. Despite the proved influence of the PG repository in the local radon concentrations, the studied periods suggest that the contribution of an external source needs to be considered. Further studies with additional measurement stations will be carried out to confirm the hypothesis of radon transport related to continental sources of the Western Mediterranean Basin. In addition, these studies could be used to determine the radon transport relation to increments of other trace gases, such as $\mathrm{SO} 2$ or NO2, which have been associated with transport from the Mediterranean Sea in ongoing studies in the region.

\section{Acknowledgements}

This research was partially supported by the Spanish Ministry of Science, Innovation and Universities, by the project "Fluxes of radionuclides emitted by the PG piles located at Huelva; assessment of the dispersion, radiological risks and remediation proposals" (Ref.: CT- 
M2015-68628-R). The authors of this work want to thank the "Agencia Española de Meteorología" (AEMET) for the meteorological data supplied. Special thanks to Antonio Padilla for his invaluable technical support and know-how, without which it would have been impossible to carry out this work.

\section{Appendix A. Supplementary data}

Supplementary data to this article can be found online at https:// doi.org/10.1016/j.atmosenv.2018.12.010.

\section{References}

Adame, J.A., Bolívar, J.P., de la Morena, B.A., Lammel A Adame Carnero, G.J., de la Morena, B.A., Bolívar, J.P., 2010a. Surface ozone measurements in the southwest of the Iberian Peninsula (Huelva, Spain). Environ. Sci. Pollut. Res. 17, 355-368 https:// doi.org/10.1007/s11356-008-0098-9.

Adame, J.A., Notario, A., Villanueva, F., Albaladejo, J., 2012. Application of cluster analysis to surface ozone, NO 2 and SO 2 daily patterns in an industrial area in Central-Southern Spain measured with a DOAS system. Sci. Total Environ. 429, 281-291 https://doi.org/10.1016/j.scitotenv.2012.04.032.

Adame, J.A., Serrano, E., Bolívar, J.P., de la Morena, B.A., Adame, J.A., Serrano, E., Bolívar, J.P., Morena, B.A. de la, 2010b. On the Tropospheric Ozone Variations in a Coastal Area of Southwestern Europe under a Mesoscale Circulation. J. Appl. Meteorol. Climatol. 49, 748-759 https://doi.org/10.1175/2009JAMC2097.1.

Arnold, D., Vargas, A., Vermeulen, A.T., Verheggen, B., Seibert, P., 2010. Analysis of radon origin by backward atmospheric transport modelling. Atmos. Environ. 44, 494-502 https://doi.org/10.1016/j.atmosenv.2009.11.003.

Beaver, S., Palazoğlu, A., 2006. A cluster aggregation scheme for ozone episode selection in the San Francisco, CA Bay Area. Atmos. Environ. 40, 713-725 https://doi.org/10. 1016/J.ATMOSENV.2005.10.003.

Bolivar, J.P., García-Tenorio, R., García-León, M., 1996. On the fractionation of natural radioactivity in the production of phosphoric acid by the wet acid method. J. Radioanal. Nucl. Chem. Lett. 214, 77-88 https://doi.org/10.1007/BF02164808.

Borge, R., Alexandrov, V., José del Vas, J., Lumbreras, J., Rodríguez, E., 2008. A comprehensive sensitivity analysis of the WRF model for air quality applications over the Iberian Peninsula. Atmos. Environ. 42, 8560-8574 https://doi.org/10.1016/j. atmosenv.2008.08.032

Botha, R., Labuschagne, C., Williams, A.G., Bosman, G., Brunke, E.-G., Rossouw, A., Lindsay, R., 2018. Characterising fifteen years of continuous atmospheric radon activity observations at Cape Point (South Africa). Atmos. Environ. 176, 30-39 https://doi. org/10.1016/J.ATMOSENV.2017.12.010.

Burton, W.M., Stewart, N.G., 1960. Use of Long-Lived Natural Radioactivity as an Atmospheric Tracer. Nature 186, 584-589 https://doi.org/10.1038/186584a0.

Chambers, S.D., Wang, F., Williams, A.G., Xiaodong, D., Zhang, H., Lonati, G., Crawford, J., Griffiths, A.D., Ianniello, A., Allegrini, I., 2015. Quantifying the influences of atmospheric stability on air pollution in Lanzhou, China, using a radon-based stability monitor. Atmos. Environ. 107, 233-243 https://doi.org/10.1016/J.ATMOSENV.2015. 02.016 .

Chambers, S.D., Williams, A.G., Conen, F., Griffiths, A.D., Reimann, S., Steinbacher, M., Krummel, P.B., Steele, L.P., Van Der Schoot, M.V., Galbally, I.E., Molloy, S.B., Barnes, J.E., 2016. Towards a Universal Baseline Characterisation of Air Masses for High-and Low-Altitude Observing Stations Using Radon-222. Aerosol Air Qual. Res. 16, 885-899 https://doi.org/10.4209/aaqr.2015.06.0391.

Dee, D.P., Uppala, S.M., Simmons, A.J., Berrisford, P., Poli, P., Kobayashi, S., Andrae, U., Balmaseda, M.A., Balsamo, G., Bauer, P., Bechtold, P., Beljaars, A.C.M., van de Berg, L., Bidlot, J., Bormann, N., Delsol, C., Dragani, R., Fuentes, M., Geer, A.J., Haimberger, L., Healy, S.B., Hersbach, H., Hólm, E.V., Isaksen, L., Kållberg, P., Köhler, M., Matricardi, M., McNally, A.P., Monge-Sanz, B.M., Morcrette, J.-J., Park, B.-K., Peubey, C., de Rosnay, P., Tavolato, C., Thépaut, J.-N., Vitart, F., 2011. The ERA-Interim reanalysis: configuration and performance of the data assimilation system. Q. J. R. Meteorol. Soc. 137, 553-597 https://doi.org/10.1002/qj.828.

Domínguez-López, D., Adame, J.A., Hernández-Ceballos, M.A., Vaca, F., De la Morena, B.A., Bolívar, J.P., 2014. Spatial and temporal variation of surface ozone, NO and NO2 at urban, suburban, rural and industrial sites in the southwest of the Iberian Peninsula. Environ. Monit. Assess. 186, 5337-5351 https://doi.org/10.1007/ s10661-014-3783-9.

Draxler, R., Stunder, B., Rolph, G., Stein, A., Taylor, A., 2018. HYSPLIT4 User's Guide.

Dudhia, J., Wang, W., 2014. WRF Advanced Usage and Best practices, vol. 35.

Dueñas, C., Liger, E., Cañete, S., Pérez, M., Bolívar, J.P., 2007. Rn from phosphogypsum piles located at the Southwest of Spain. In: https://doi.org/10.1016/j.jenvrad.2007. 01.012

Everitt, B.S., Landau, S., Leese, M., Stahl, D., 2011. Cluster Analysis, Quality and Quantity. In: https://doi.org/10.1007/BF00154794.
Grossi, C., Arnold, D., Adame, J.A., López-Coto, I., Bolívar, J.P., De La Morena, B.A., Vargas, A., 2012. Atmospheric 222Rn concentration and source term at El Arenosillo 100 m meteorological tower in southwest Spain. Radiat. Meas. 47, 149-162 https://doi. org/10.1016/j.radmeas.2011.11.006

Grossi, C., Vogel, F.R., Curcoll, R., Àgueda, A., Vargas, A., Rodó, X., Morguí, J.-A., 2018. Study of the daily and seasonal atmospheric $\mathrm{CH} 4$ mixing ratio variability in a rural Spanish region using 222Rn tracer. Atmos. Chem. Phys. 18, 5847-5860 https://doi. org/10.5194/acp-18-5847-2018.

Hernández-Ceballos, M.A., 2012. Caracterización meteorológica y modelización de Andalucía occidental. University of Huelva.

Hernández-Ceballos, M.A., Vargas, A., Arnold, D., Bolívar, J.P., 2015. The role of mesoscale meteorology in modulating the ${ }^{222} \mathrm{Rn}$ concentrations in Huelva (Spain) impact of phosphogypsum piles. J. Environ. Radioact. 145, 1-9 https://doi.org/10. 1016/j.jenvrad.2015.03.023

Hong, S.-Y., Noh, Y., Dudhia, J., Hong, S.-Y., Noh, Y., Dudhia, J., 2006. A New Vertical Diffusion Package with an Explicit Treatment of Entrainment Processes. Mon. Weather Rev. 134, 2318-2341 https://doi.org/10.1175/MWR3199.1.

Janjić, Z.I., 1994. The Step-Mountain Eta Coordinate Model: Further Developments of the Convection, Viscous Sublayer, and Turbulence Closure Schemes. Mon. Weather Rev. 122, 927-945 https://doi.org/10.1175/1520-0493(1994)122<0927:TSMECM > 2.0. $\mathrm{CO} ; 2$.

Karstens, U., Schwingshackl, C., Schmithüsen, D., Levin, I., 2015. A process-based ${ }^{222}$ radon flux map for Europe and its comparison to long-term observations. Atmos. Chem. Phys. 15, 12845-12865 https://doi.org/10.5194/acp-15-12845-2015.

López-Coto, I., 2011. Variabilidad espacial y temporal de fuentes y concentraciones de radón en la baja atmósfera. University of Huelva.

López-Coto, I., Mas, J.L., Bolívar, J.P., 2013. A 40-year retrospective European radon flux inventory including climatological variability. Atmos. Environ. 73, 22-33 https://doi. org/10.1016/j.atmosenv.2013.02.043.

López-Coto, I., Mas, J.L., Vargas, A., Bolívar, J.P., 2014. Studying radon exhalation rates variability from phosphogypsum piles in the SW of Spain. J. Hazard Mater. 280, 464-471 https://doi.org/10.1016/j.jhazmat.2014.07.025.

Lükewille, A., 2008. The application of models under the European Union's Air Quality Directive: A technical reference guide.

Mas, J.L., San Miguel, E.G., Bolívar, J.P., Vaca, F., Pérez-Moreno, J.P., 2006. An assay on the effect of preliminary restoration tasks applied to a large TENORM wastes disposal in the south-west of Spain. Sci. Total Environ. 364, 55-66 https://doi.org/10.1016/j. scitotenv.2005.11.006.

Moore, H.E., Poet, S.E., Martell, E.A., 1973. 222 Rn, 210 Pb, 210 Bi, and 210 Po profiles and aerosol residence times versus altitude. J. Geophys. Res. 78, 7065-7075 https:// doi.org/10.1029/JC078i030p07065.

Pielke, R.A., 2002. Mesoscale Meteorological Modeling, Mesoscale Meteorological Modeling. In: https://doi.org/10.1016/C2009-0-02981-X.

Pleim, J.E., 2007. A Combined Local and Nonlocal Closure Model for the Atmospheric Boundary Layer. Part I: Model Description and Testing. J. Appl. Meteorol. Climatol. 46, 1383-1395 https://doi.org/10.1175/JAM2539.1.

Podstawczyńska, A., 2016. Differences of near-ground atmospheric Rn-222 concentration between urban and rural area with reference to microclimate diversity. Atmos. Environ. 126, 225-234 https://doi.org/10.1016/J.ATMOSENV.2015.11.037.

Porstendörfer, J., Butterweck, G., Reineking, A., 1991. Diurnal variation of the concentrations of radon and its short-lived daughters in the atmosphere near the ground. Atmos. Environ. Part A, Gen. Top. https://doi.org/10.1016/0960-1686(91)90069-J.

Schery, S.D., Huang, S., 2004. An estimate of the global distribution of radon emissions from the ocean. Geophys. Res. Lett. 31, L19104 https://doi.org/10.1029/ 2004 GL021051.

Seaman, N.L., Gaudet, B.J., Zielonka, J., Stauffer, D.R., 2009. Sensitivity of vertica structure in the stable boundary layer to variations of the WRF model's Mellor-Yamada-Janjic turbulence scheme. In: 10th WRF Users' Workshop.

Skamarock, C., Klemp, B., Dudhia, J., Gill, O., Barker, D., Duda, G., Huang, X., Wang, W., Powers, G., 2008. A Description of the Advanced Research WRF Version 3. In: https: //doi.org/10.5065/D68S4MVH.

UNSCEAR, 2000. Sources and Effects of Ionizing Radiation, vol. I, United Nations Publication.

Vargas, A., Arnold, D., Adame, J.A., Grossi, C., Hernández-Ceballos, M.A., Bolívar, J.P., 2015. Analysis of the vertical radon structure at the spanish "El arenosillo" tower station. J. Environ. Radioact. 139, 1-17 https://doi.org/10.1016/j.jenvrad.2014.09.018.

Vargas, A., Ortega, X., 2006. Influence of environmental changes on continuous radon monitors. Results of a Spanish intercomparison exercise. Radiat. Protect. Dosim. 121, 303-309 https://doi.org/10.1093/rpd/ncl036.

Vargas, A., Ortega, X., Matarranz, J.L.M., 2004. Traceability of radon-222 activity concentration in the radon chamber at the technical university of Catalonia (Spain). Nucl. Instruments Methods Phys. Res. Sect. A Accel. Spectrometers, Detect. Assoc. Equip. 526, 501-509 https://doi.org/10.1016/j.nima.2004.02.022.

Wilkening, M.H., 1952. Natural Radioactivity as a Tracer in the Sorting of Aerosols According to Mobility. Rev. Sci. Instrum. 23, 13-16 https://doi.org/10.1063/1.1746056. 